\title{
Obesity and Disability The Shape of Things to Come
}

RAND RESEARCH AREAS

THE ARTS

CHILD POLICY

CIVIL JUSTICE

EDUCATION

ENERGY AND ENVIRONMENT

HEALTH AND HEALTH CARE

INTERNATIONAL AFFAIRS

NATIONAL SECURITY

POPULATION AND AGING

PUBLIC SAFETY

SCIENCE AND TECHNOLOGY

SUBSTANCE ABUSE

TERRORISM AND

HOMELAND SECURITY

TRANSPORTATION AND

INFRASTRUCTURE

WORKFORCE AND WORKPLACE

This product is part of the RAND Corporation research brief series. RAND research briefs present policy-oriented summaries of published, peer-reviewed documents.

Corporate Headquarters 1776 Main Street P.O. Box 2138 Santa Monica, California 90407-2138 TEL 310.393 .0411 FAX 310.393 .4818 (c) RAND 2007
A merica appears to be in the midst of an obesity epidemic. Should we care?

RAND Corporation researchers have conducted a series of studies analyzing obesity trends and estimating their effects on future health care costs. They found that

- obesity in the U.S. population has been increasing steadily over the past two decades - and severe obesity is increasing the fastest

- obesity translates into higher health care costs and contributes to disability at all ages

- traditional clinical approaches, in particular bariatric surgery, cannot slow the trend

- Medicare and Medicaid savings stemming from increasingly good health among the elderly could be swamped by the cost consequences of disability among the young.

\section{What Is Obesity?}

Obesity is weight that endangers health because of its high body fat relative to lean body mass. A good screener for obesity is the Body Mass Index (BMI). BMI is a person's weight in kilograms, divided by height in meters squared. The table illustrates how the BMI is used. For example, a man or woman who is 5'6" tall and weighs 115 to 154 pounds is within the normal weight range, overweight at 155 to 185 pounds, and obese at 186 pounds or more. Because the BMI does not distinguish fat from bone and muscle mass, it can misclassify some people.

\section{Key findings:}

- Obesity in the U.S. population has been increasing steadily over the past two decades-and severe obesity is increasing the fastest.

- Obesity is linked to higher health care costs than smoking or drinking, and plays a major role in disability at all ages.

- The explosive increase in bariatric surgery has had no noticeable effect on the prevalence of severe obesity.

- The cost consequences of disability among the young could swamp recent Medicare and Medicaid savings stemming from increasingly good health among the elderly.

\section{Is Obesity Really a Problem?}

More than one in five U.S. adults are now classified as obese based on self-reported weight, and almost one in three based on objectively measured weight. What do such statistics mean for health and health care costs?

Economist Roland Sturm examined data from Healthcare for Communities, a national household telephone survey of about 10,000 respondents ages 18 to 65 conducted in 1998 . He found that obesity is associated with more chronic medical conditions than smoking or

Measuring Obesity: Examples (in pounds)

\begin{tabular}{|c|c|c|c|}
\hline Height & Normal & Overweight & Obese \\
\hline $5^{\prime} 6^{\prime \prime}$ & 115 to 154 & 155 to 185 & 203 or more \\
\hline $5^{\prime} 9^{\prime \prime}$ & 125 to 168 & 169 to 202 & 221 or more \\
\hline $6^{\prime}$ & 137 to 183 & 184 to 220 & \\
\hline
\end{tabular}


Figure 1

The Link Between Obesity and Chronic Conditions

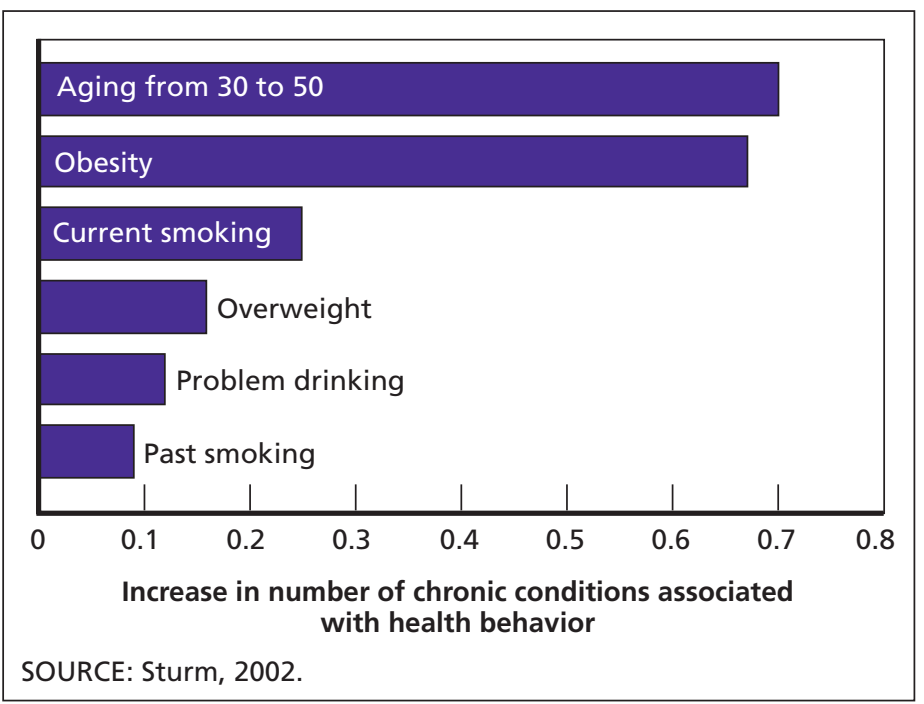

problem drinking (see Figure 1). Only aging 20 years (from 30 to 50 ) has comparable effects.

Because of their health problems, obese individuals incur higher health care costs than current smokers or problem drinkers. Compared with their normal-weight counterparts, the obese spend 36 percent more on health care services, and 77 percent more on medications; the comparable numbers for current smokers are 21 percent and 28 percent, respectively, and less for problem drinkers.

\section{The Trend Isn't Promising}

Sturm also found that the fastest-growing group of obese Americans consists of people who are at least 100 pounds overweight. Between 1987 and 2005, the prevalence of a BMI greater than 40 (about 100 pounds overweight) increased by 500 percent; the prevalence of a BMI greater than 50 increased by almost 1,000 percent, much faster than the prevalence of moderate obesity, which "merely" tripled (see Figure 2). In fact, just between 2000 and 2005, the prevalence of a BMI over 40 (indicating clinically severe obesity) increased by 50 percent. This finding challenges the belief of many physicians that clinically severe obesity is a rare pathological condition affecting only a fixed percentage of the population. Instead, the finding is consistent with the view of most epidemiologists that severe obesity is an integral part of the U.S. population's weight distribution-and as everybody gets heavier, the extreme group has the fastest growth rate.

The rapid growth in the proportion of Americans with clinically severe obesity has enormous implications for the nation's health care system. Severely obese people are more than twice as likely as people of normal weight to be in
Figure 2

Severe Obesity Rates Are Increasing Fastest

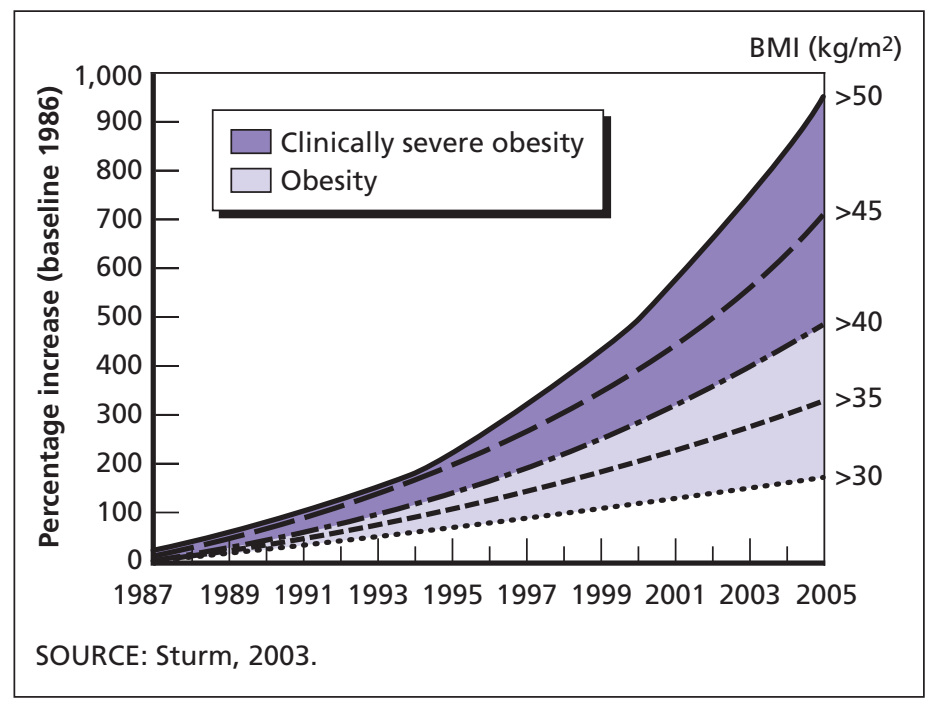

fair or poor health and have about twice as many chronic medical conditions. This translates into higher health care costs-69 percent higher for men, 60 percent higher for women-compared with people of normal weight.

Weight also has a dramatic effect on people's ability to manage five basic activities of daily living: bathing, eating, dressing, walking across a room, and getting in or out of bed. For men, severe obesity is associated with a 300 percent increased probability of having limitations on these activities. The effects are even larger for women.

\section{Has Obesity Played a Role in Rising Disability Among the Young?}

The relationship between obesity and disability for individuals may now be playing out on the national stage. Economist Darius Lakdawalla and his colleagues found that disability rates for people ages 30-59 have increased significantlythe sharpest rise was for individuals 30-39, whose disability rates increased by nearly 50 percent (see Figure 3 ). These increases were not confined to the less educated or to the poor, but occurred across all demographic and economic groups.

All the reasons for deteriorating health are not yet known; however, the rise in obesity seems likely to have played a role. Since obese people are more disabled than the non-obese, more obese people means more disabled people.

This simple phenomenon can explain a significant fraction of the growth in disability (see Figure 4). Moreover, although mental health is among the most important causes of disability among the non-elderly, the fastest-growing causes are diabetes and musculoskeletal problems - conditions that are associated with obesity. 


\section{What If Obesity Trends Continue?}

The increase in obesity rates could slow. But what if the increase continues at its current rate? To answer that question, Sturm and his colleagues drew on two national surveys: They estimated the link between obesity and health and combined that estimate with historical obesity trends, extrapolated to 2020 .

If historical obesity trends were to continue through 2020 without other changes in behavior or medical technology, the proportion of individuals reporting fair or poor health would increase by about 12 percent for men and 14

\section{Figure 3}

Increases in Disability Rates, 1984-1996

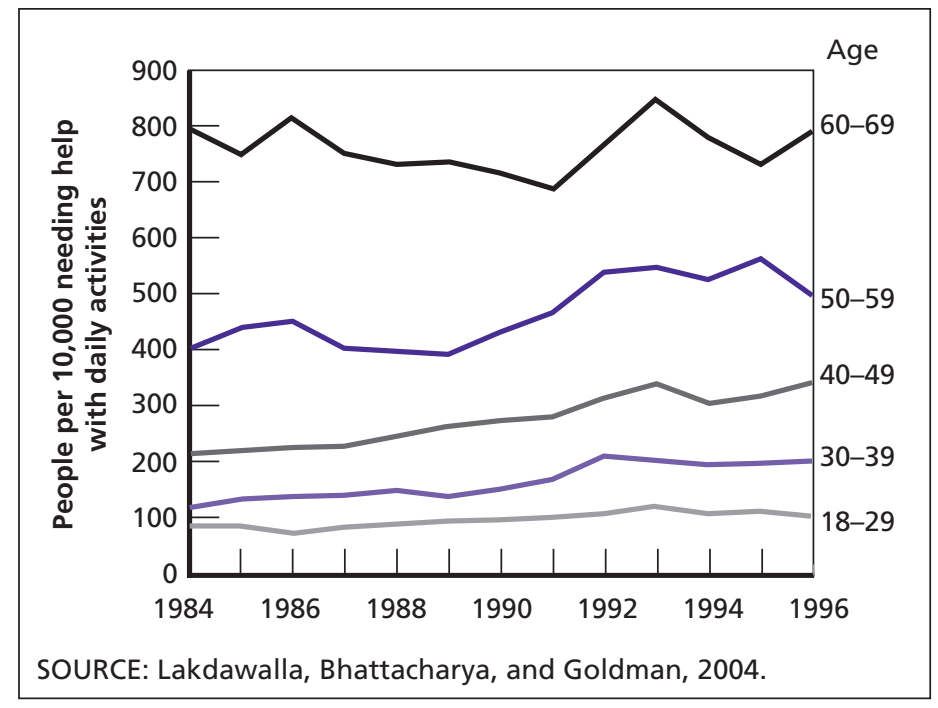

\section{Figure 4}

Obesity Accounts for a Substantial Part of Increased Disability in All Age Groups

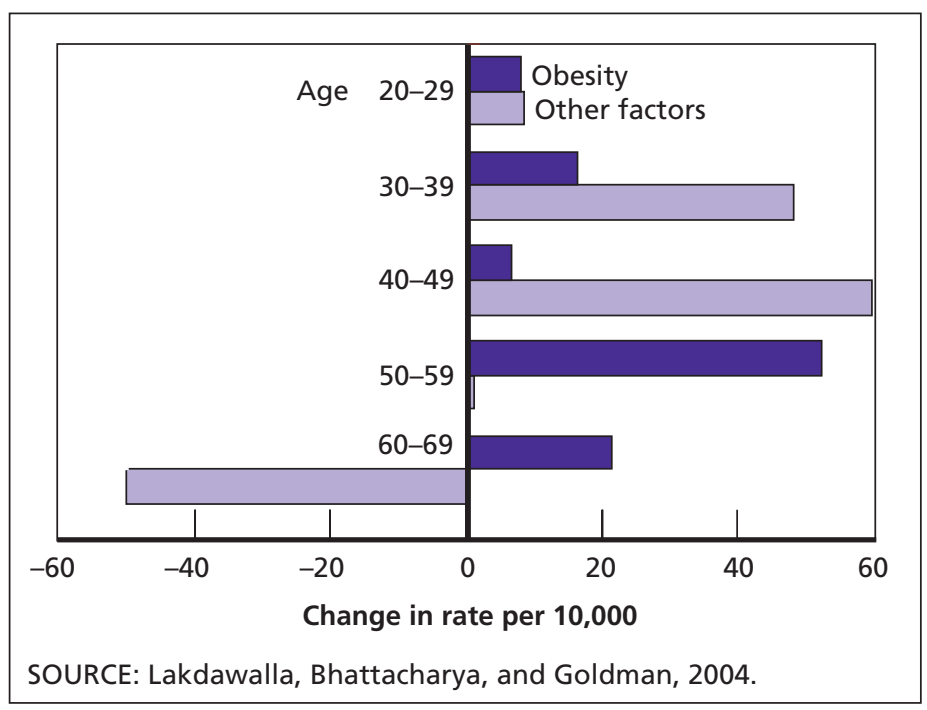

percent for women, compared with 2000. Up to one-fifth of health care expenditures would be devoted to treating the consequences of obesity (see Figure 5). And rising disability rates could offset past reductions in disability (see Figure 6).

Lakdawalla and his colleagues analyzed how a sustained increase in disability rates would affect the number of residents in U.S. nursing homes. They predicted that the nursing home population would likely grow $10-25$ percent more than historical disability trends predict.

Such growth would have dramatic effects on Medicaid, which funds more than three-quarters of long-term care in

Figure 5

One-Fifth of Health Care Expenditures Would Be Devoted to Treating the Consequences of Obesity

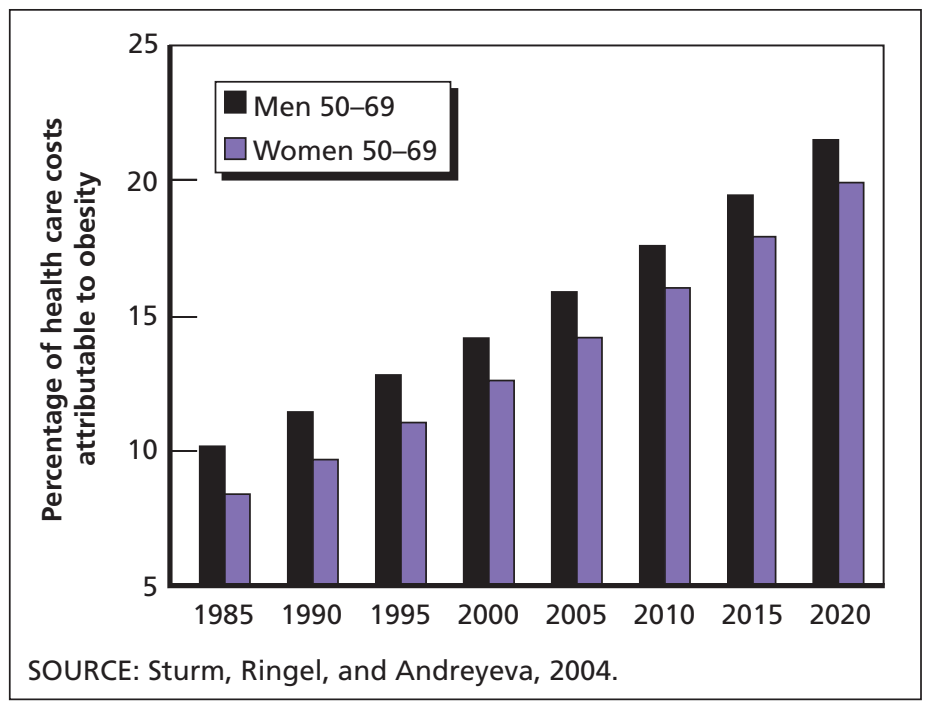

Figure 6

Rising Disability Rates Would Offset Past Reductions in Disability

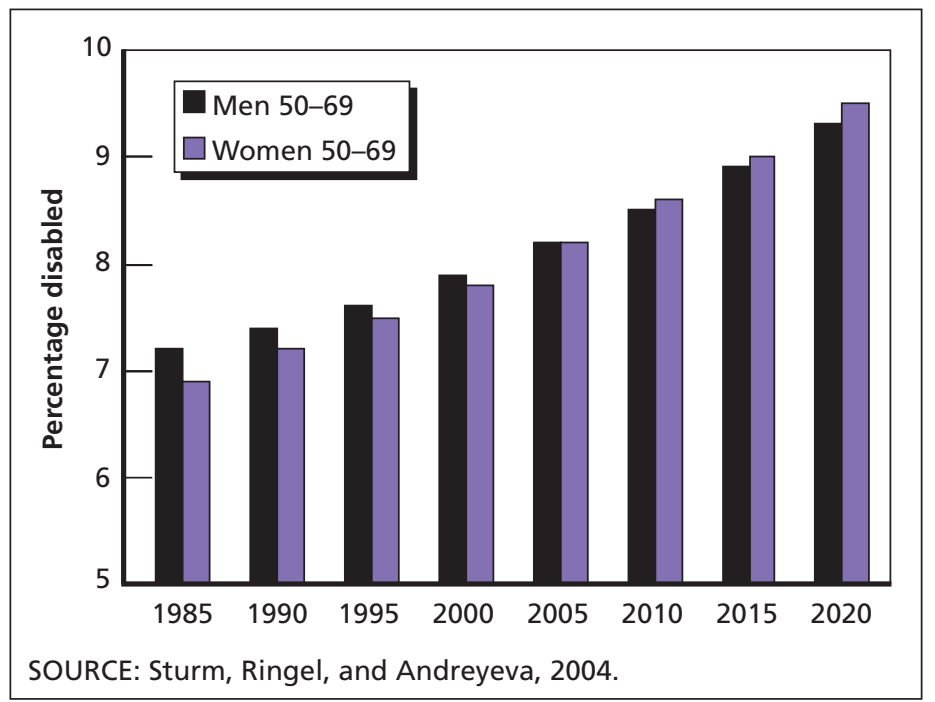


the country. For example, in 2001, the state of New York spent about $\$ 5.4$ billion on long-term care. That number could rise by as much as 5 percent in 2016, increasing the state's per-capita Medicaid expenditures on long-term care from about $\$ 280$ to as much as $\$ 350$.

It is also possible that increased demand for space in nursing homes would cause nursing home costs to rise sharply, and Medicaid eligibility would contract to limit growth in nursing home residency. In this case, the greatest costs would be borne not by governments but by sick and disabled individuals who might not be able to afford the higher price of a nursing home.

\section{Looking to the Future}

Individuals who are obese face greater challenges in terms of disability and chronic disease than do their non-obese counterparts. However, their personal challenges also translate into major issues for public budgets and for society at large.

\section{This Highlight summarizes RAND Health research reported in the following publications:}

Lakdawalla, D. N., J. Bhattacharya, and D. P. Goldman, "Are the Young Becoming More Disabled?" Health Affairs, Vol. 23, No. 1, January/ February 2004, pp. 168-176.

Lakdawalla, D., D. P. Goldman, J. Bhattacharya, M. D. Hurd, G. F. Joyce, and C.W.A. Panis, "Forecasting the Nursing Home Population," Medical Care, Vol. 41, No. 1 (Point/Counterpoint), 2003, pp. 8-20.

Sturm, R., "The Effects of Obesity, Smoking, and Drinking on Medical Problems and Costs," Health Affairs, Vol. 21, No. 2, March/April 2002, pp. $245-253$.

Sturm, R., "Increases in Clinically Severe Obesity in the United States, 1986-2000," Archives of Internal Medicine, Vol. 163, No. 18, October 13, 2003, pp. 2146-2148.

Sturm, R., J. Ringel, and T. Andreyeva, "Increasing Obesity Rates and Disability Trends," Health Affairs, Vol. 23, No. 2, March/April 2004, pp. 1-7.

Sturm, R., "Increases in Morbid Obesity in the USA: 2000-2005," Public Health, 2007. As of April 6, 2007:

http://dx.doi.org/10.1016/j.puhe.2007.01.006

Abstracts of all RAND Health publications and full text of many research documents can be found on the RAND Health Web site at www.rand.org/health. The RAND Corporation is a nonprofit research organization providing objective analysis and effective solutions that address the challenges facing the public and private sectors around the world. RAND's publications do not necessarily reflect the opinions of its research clients and sponsors. RAND ${ }^{\circledR}$ is a registered trademark. 
THE ARTS

CHILD POLICY

CIVIL JUSTICE

EDUCATION

ENERGY AND ENVIRONMENT

HEALTH AND HEALTH CARE

INTERNATIONAL AFFAIRS

NATIONAL SECURITY

POPULATION AND AGING

PUBLIC SAFETY

SCIENCE AND TECHNOLOGY

SUBSTANCE ABUSE

TERRORISM AND HOMELAND SECURITY

TRANSPORTATION AND INFRASTRUCTURE

WORKFORCE AND WORKPLACE
This PDF document was made available from www.rand.org as a public service of the RAND Corporation.

This product is part of the RAND Corporation research brief series. RAND research briefs present policy-oriented summaries of individual published, peerreviewed documents or of a body of published work.

The RAND Corporation is a nonprofit research organization providing objective analysis and effective solutions that address the challenges facing the public and private sectors around the world.

\section{Support RAND}

$\underline{\text { Browse Books \& Publications }}$

Make a charitable contribution

For More Information

Visit RAND at www.rand.org

Explore RAND Health

View document details

Limited Electronic Distribution Rights

This document and trademark $(s)$ contained herein are protected by law as indicated in a notice appearing later in this work. This electronic representation of RAND intellectual property is provided for noncommercial use only. Permission is required from RAND to reproduce, or reuse in another form, any of our research documents for commercial use. 